\title{
Hedges and Boosters as Modality Markers: An Analysis of Nigerian and American Editorials
}

\author{
Oluwasola Emmanuel Ojo \\ University of Ilorin, NIGERIA \\ e-mail: emmania2012@gmail.com
}

\begin{abstract}
Many studies have been carried out on the use of hedges and boosters as persuasive strategies, but little is known about their employment when texts such as editorials are compared cross culturally. This study comparatively examined the employment of modality markers to express doubt and conviction in Nigerian and American editorials. Farrokhi and Emami's (2008) classification of hedges and boosters was employed to analyze twenty editorials selected from two Nigerian newspapers and two American newspapers. Findings reveal that both sets of editorial writers made use of hedges and boosters a lot in their writings. However, lexical verbs were not employed as boosters in the analyzed editorials. The fact that the Nigerian editorial writers as ESL writers equally made great use of hedges and boosters implies that in texts such as editorials, writers from different cultures equally employ the same linguistic devices to express doubt and conviction.
\end{abstract}

Keywords: Editorials; modality markers; hedges; boosters; persuasion; doubt; conviction.

\section{INTRODUCTION}

Over the years, there has been a growing interest in the study of editorial as a genre. An editorial is generally regarded as an article in a newspaper, whether in hardcopy or online, that reflects the view and opinion of the editor, publisher or owner of the newspaper on a specific issue (Ansary \& Babaii, 2004; Medubi, 2007). According to Van Dijk (1996), editorials "are probably the widest circulated opinion discourse of society whether or not all readers of the newspaper read them daily. Their influence may not so be based on massive popular influence, as rather on their influence on elites" (p. 18). Editorials are written in newspapers, magazines, periodicals and journals. Unlike newspaper columns, where columnists make use of first person pronouns and stories of personal experiences, editorials are impersonal and only deal with social, cultural, economic, religious and political issues that are of great value to the general public (Jegede, 2015; Medubi, 2007). It is believed that the policies and actions of government are sometimes directed by the opinions expressed in the editorials as most people in government are influenced by the views of most respected newspapers. It is on these various issues that the ideological stance of a newspaper is reflected. And this has probably drawn the attention of researchers to editorials.

Editorial has its peculiar features, language, style and functions. Medubi (2007, p. 116) submitted that the editorial must remain simple enough for everyone to understand; must also not lose its aesthetic appeal; should adopt a lofty tone; should provide enlightenment on issues; should show completeness in the sense of presenting well researched issues; and should be presented from position of knowledge. However, in writing editorials, writers need to balance their claims between conviction and caution. This is done by using words that express the writers' confidence in the reliability of their claims or express tentativeness in order to display uncertainty. These words are communicative strategies that are used to increase and reduce the force of claims in writing (Farrokhi \& Emami, 2008; Holmes, 1982; Hyland, 1998) and they are referred to as hedges and boosters. Hedges are lexical devices that are employed to reduce the force of conviction of the utterance. They also help the writers to be free of accusations or criticisms that may emanate from the claims in their writings. On the other hand, boosters are referred to as certainty markers or emphatics and are used by writers to present their claims with strong conviction and total commitment.

Many studies have been carried out on the use of lexical devices or rhetorical tools as hedges and boosters in various forms of writings. In some studies, they are referred to as modal elements. Modality has to do with the validity of the information being exchanged in terms of probability or usuality. Modality is a rhetorical tool that helps in identifying the attitudes, opinions, and commitment of the speakers/writers towards their propositions. In the submission of Fowler (1986), cited by Alo (2013), modality is "the grammar 
of explicit comment, the means by which people express their degree of commitment to the truth of the propositions they utter, and their views on the desirability or otherwise of the states of affairs referred to" (p. 127). Therefore, modality markers are rhetorical tools used by editorial writers to inform and encourage their readers to agree with their propositions. However, in this study, hedges and boosters as modality markers are examined specifically in terms of the degree of commitment of editorial writers.

Editorial writers are products of different cultural backgrounds; the rhetorical patterns of their cultures may therefore reflect in their writings. According to Swales (1996) and Van Dijk (1985, 1996) cited in Ansary and Babaii (2009), "the rhetorical patterns of one's native culture-linguistic system are likely to be more pronounced in texts such as editorials" (p. 213). The need to study editorials cross-culturally is summed up by Connor (1996) when she argues that "research on editorials cross-culturally is significant" and that "little is known cross-culturally about the genre" (p. 144).

Based on the argument for cross-cultural studies of editorials, Sedaghat, et al. (2015) carried out a study to investigate the rhetorical patterns of editorials and employment of lexical devices as hedges and boosters in editorials. They investigated the use of hedges in English and Persian newspaper editorials by employing Salager-Meyer's (1994) classification of hedges. Also, Farrokhi and Emami (2008) examined the use of lexical devices as hedges and boosters in the native and non-native research articles in two disciplines. They employed Holmes' (1988) categories of lexical devices as hedges and boosters. Although the classification by Holmes was employed by Farrokhi and Emami to analyze research articles, it is being used in this study to analyze editorials in Nigerian and American newspapers.

Based on the foregoing, this study is aimed at finding out if there are significant differences in the employment of the categories of hedges and boosters in Nigerian and American editorials as reflected in the data assembled for this study. Also, the study investigates if all the categories of lexical devices are employed in both the Nigerian and American editorials selected for this study.

\section{Empirical Studies on Hedges, Boosters and Editorials}

Hinkel submits that hedging is the "use of linguistic devices to decrease the writer's responsibility for the extent of and the truth value of propositions/claims, to show hesitation or uncertainty, and/or to display politeness, and indirectness in order to reduce their imposition on the writer or the reader" (2002, p. 148).
In other words, they are used to express caution and uncertainty concerning the truth value of propositions. Thue Vold (2006), cited in Farrokhi and Emami (2008) submitted that there are two types of hedges: real hedges and strategic hedges. Real hedges are not meant to express politeness or modesty but to express real uncertainty. In other words, they are used to express the real situation of claims, especially in scientific researches where certain claims or conclusions cannot be made (Lewin, 2005). However, strategic hedges are used by writers in order to be modest, polite and cautious. Thus, when a writer is not certain of his claim, he uses strategic hedges.

On the other hand, boosters are communicative devices that writers use to "express conviction and assert a proposition with confidence, representing a strong claim about a state of affairs" (Hyland, 1998, p. 350). Through the employment of boosters, writers are able to assert decisiveness and conviction in their propositions. Through terms such as "certainty markers" (Crismore, et al., 1993) and "intensifying features" (Myers, 1989), studies have been conducted on boosters. Unlike hedges, boosters have not been studied extensively (Vassileva, 2001). However, both hedges and boosters are important linguistic tools for writers, especially of persuasive texts, who express both doubt and certainty in their propositions.

On the functions of hedges and boosters, Holmes (1982) came up with two functions: expression of modal meaning and expression of affective meaning. Modal meaning has to do with the speaker's attitude to the content of the proposition (Holmes, 1982; Farrokhi \& Emami, 2008) while affective meaning has to do with the attitude of the speaker to his addressee or audience while also "taking account of the function and the illocutionary force of utterances" (Holmes, 1982, p. 18). Also, Hyland argued that they "work to balance objective information, subjective evaluation and interpersonal negotiation, and this can be a powerful persuasive factor in gaining acceptance for claims" (1998, p. 353). In other words, both hedges and boosters function as expressions of writer's uncertainty and conviction, and their employments in persuasive texts such editorials have been investigated.

In a study carried out by Sedaghat, et al (2015), the use of hedges in English and Persian newspaper editorials was examined. 30 editorials, 15 in each language, were analyzed. The five types of hedges: shields, approximates of degree, quantity, frequency and time, author's personal doubt and direct involvement and compound hedges introduced in Salager-Meyer's (1994) taxonomy were employed. They found out that hedges were used more in English editorials than in Persian editorials. In other words, they believed that there are cultural variations in the employment of hedges by writers from different cultures. 
In a study on Nigerian editorials, Jegede (2015) examined the language and ideology in newspapers editorials by looking at the process types of Systemic Functional Linguistics. He found out that different process types are expressed in Nigerian editorials and that they are "used to describe or make references to authorities in the nation, citizens, social bodies, political and social values..." (2015, p. 83). He concluded that through the analytical framework of Systemic Functional Linguistics, the "deeper nuances of meaning" are discernible to the editorial readers.

Farrokhi and Emami (2008) examined the employment of hedges and boosters in the research articles of two disciplines of Electrical Engineering and Applied Linguistics. This was done by exploring the use of hedges and boosters by native and non-native writers of English in the research articles. They found out that hedges and boosters are employed more in Applied Linguistics than in Electrical Engineering. Also, they found out that there are similarities and differences in the use of hedges and boosters by the native and non-native writers.

In Electrical Engineering articles, the native and nonnative writers mostly used modal verbs and adverbs to express hedging. In a similar way, the native and nonnative writers in Applied Linguistics articles mostly made use of lexical verbs, modal verbs and adverbs as hedges. Also, in both disciplines, the native and nonnative writers equally made use of lexical verbs as the most used lexical device as boosters. However, there are differences in the use of hedges and boosters in the two disciplines. The native writers employed more adverbs ( 35 occurrences) than the non-native writers (13 occurrences) as boosters in Applied Linguistics articles.

From the review of studies that have been carried out to investigate hedges, boosters and editorials, it is observable that editorials have been investigated in terms of language and ideology, and employment of hedges and boosters. The use of hedges as doubting expressions in various forms of writing has been extensively investigated. However, few studies have examined the use of hedges in editorials on one hand, and the use of both hedges and boosters on the other hand. Therefore, as it is necessary for editorial writers to balance their propositions through the expressions of doubt and certainty, the justification for this study is that there is a need to cross-culturally investigate the employment of both hedges and boosters in Nigerian and American editorials.

In this study, Farrokhi and Emami's (2008) classification of lexical devices that function as hedges and boosters is adapted. Farrokhi and Emami modified Holmes' (1988) classification to analyze the use of hedges and boosters in academic writing of native and non-native research article by including clausal elements in their own analysis. Thus, there are six categories of lexical devices in their classification, instead of the five proposed by Holmes. They are: modal verbs, lexical verbs, adverbs, adjectives, nouns and clausal elements.

For the purpose of this study, a modification to Farrokhi and Emami's (2008) classification is made. Attributor as a category is added as one of the lexical devices for hedges. Generally, attributors are referred to as the sources of information of writers' claims. This lexical device can also be used to express total conviction for a claim but its main function is to lessen the force of the commitment of a writer to a claim. Thus, they are regarded as hedges. The table below shows all the categories of hedges and boosters with some examples as compiled by Farrokhi and Emami (2008) from Quirk et al. (1985), Holmes (1988), Hyland (1996, 1998), Hyland and Milton (1997) and Varttala (2001):

Table 1. A Modified Category of Hedges and Boosters with Examples.

\begin{tabular}{|c|c|c|}
\hline Categories & Hedges & Boosters \\
\hline Modal verbs & Can, could, may, might, should, will, would & Can't, couldn't, have to, must, will, won't, would \\
\hline Lexical verbs & $\begin{array}{l}\text { Appear, argue, assert, assume, attempt (to), believe, doubt, } \\
\text { estimate, imply, indicate, report, seem, speculate, think }\end{array}$ & $\begin{array}{l}\text { Assure, confirm, demonstrate, do, establish, find, } \\
\text { indicate, know, predict, reinforce, show }\end{array}$ \\
\hline Adverbs & $\begin{array}{l}\text { About, allegedly, almost, apparently, approximately, around, } \\
\text { arguably, barely, commonly, considerably, fairly, given that, } \\
\text { greatly, hardly, highly, largely, likely, maybe, nearly, perhaps, } \\
\text { unlikely }\end{array}$ & $\begin{array}{l}\text { Absolutely, actually, always, assuredly, basically, } \\
\text { certainly, clearly, completely, definitely, entirely, } \\
\text { evidently, exactly, fully, indeed, in fact, never }\end{array}$ \\
\hline Adjectives & $\begin{array}{l}\text { Apparent, approximate, common, considerable, frequent, } \\
\text { improbable, large, likely, possible, probable, usual }\end{array}$ & $\begin{array}{l}\text { Absolute, certain, clear, complete, confident, } \\
\text { definite, evident, exact, obvious, sure }\end{array}$ \\
\hline Nouns & $\begin{array}{l}\text { Alternative, assumption, belief, chance, claim, doubt, hope, idea, } \\
\text { implication, indication, opinion, possibility, tendency }\end{array}$ & $\begin{array}{l}\text { Certainty, conviction, confidence, evidence, fact, } \\
\text { precision, truth }\end{array}$ \\
\hline Clausal elements & $\begin{array}{l}\text { If it is true, it gives the impression, in my/our view, it is more } \\
\text { of... }\end{array}$ & $\begin{array}{l}\text { As a matter of fact, without any contradiction, } \\
\text { nothing can be achieved, }\end{array}$ \\
\hline Attributors & $\begin{array}{l}\text { According to the president, the governor tweeted, the report stated } \\
\text { that..., the young professor said... }\end{array}$ & \\
\hline
\end{tabular}




\section{METHODOLOGY}

The data for this study comprised twenty editorials selected from Nigerian and American daily newspapers. Ten editorials were selected from two Nigerian newspapers: The Punch and The Nigerian Tribune, and ten editorials were also selected from two American newspapers: The New York Times and The Washington Post. The editor-in-chiefs of the two Nigerian newspapers are non-native writers of English language while the editorial page editors of the selected American newspapers are native writers. All the selected editorials were written in December, 2018. The topics of the editorials are related as they are on insecurity (terror attacks and murders), politics and election matters. The study focused on the use of hedges and boosters as classified by Farrokhi and Emami (2008) in the data. All the six grammatical classes for the expression of doubt and certainty that are introduced by them and the one (attributors) that is added for the purpose of this study are employed in the study. All the linguistic devices were first identified and then analyzed by considering the context in which such linguistic devices are used. As Farrokhi and Emami submitted, "a single linguistic form such as could, for example, can express ability and permission as well as possibility" (2008, p. 73). This is exemplified from the data for this study:

Candidate Donald Trump once invited Russia to find Ms. Clinton's emails, sending the message that it could (permission) meddle with impunity (The Washington Post editorial).

The package could (possibility) prove awkward for Republican members in other areas as well (The New York Post editorial).

Therefore, the identification of any of these lexical devices does not necessarily translate to an expression of doubt or certainty. Thus, one needs to look at the context in which such a lexical device has been used. The expression of hedges and boosters were then examined for their frequency of occurrence while the results were presented in statistical forms.

\section{FINDINGS AND DISCUSSION}

The analysis of the data that constitute this study further establishes the fact that the employment of hedges and boosters is very essential in writing editorials. Editorial writers usually strike a balance between expressions of detachment (doubt) and conviction. In other words, hedges are used to show caution by withholding total commitment to a proposition while boosters are used to express strong confidence and certainty in a claim. The analysis showed that both hedges and boosters are extensively used in the data.
Concerning the use of hedges in the analyzed Nigerian editorials, the analysis revealed that modal verbs were the most used hedging expressions. Out of 149 hedges from the seven lexical devices analyzed, 43 (28.9\%) are modal verbs. This is followed by 33 lexical verbs (22.1\%), 25 attributors (16.8\%), 24 adverbs (16.1\%), 15 clausal elements $(10.1 \%)$ and 7 adjective (4.7\%). The least used lexical device is nouns with just 2 (1.3\%) occurrences. On the use of hedges in the analyzed American editorials, the analysis showed that 155 lexical devices were employed as hedges. Modal verbs had the highest frequency of occurrence of 68 (43.9\%). This is followed by $22(14.2 \%)$ lexical verbs, $22(14.2 \%)$ attributors, 21 (13.5\%) adverbs, 9 (5.8\%) clausal elements, 8 (5.2\%) adjectives while the lexical device with the least occurrence was nouns with 5 occurrences $(3.2 \%)$. The table below shows the frequency of occurrence of hedges in both Nigerian and American editorials.

Table 2. Frequency of Occurrence of Hedges Categories in Nigerian and American editorials

\begin{tabular}{lcccc}
\hline \multirow{2}{*}{$\begin{array}{c}\text { Hedges } \\
\text { categories }\end{array}$} & \multicolumn{2}{c}{ Nigerian editorials } & \multicolumn{2}{c}{ American editorials } \\
\cline { 2 - 5 } & Frequency & Percentage & Frequency & Percentage \\
\hline Modal verbs & 43 & $28.9 \%$ & 68 & $43.9 \%$ \\
Lexical verbs & 33 & $22.1 \%$ & 22 & $14.2 \%$ \\
Adverbs & 24 & $16.1 \%$ & 21 & $13.5 \%$ \\
Adjectives & 07 & $4.7 \%$ & 08 & $5.2 \%$ \\
Nouns & 02 & $1.3 \%$ & 05 & $3.2 \%$ \\
Clausal elements & 15 & $10.1 \%$ & 09 & $5.8 \%$ \\
Attributors & 25 & $16.8 \%$ & 22 & $14.2 \%$ \\
\hline Total & $\mathbf{1 4 9}$ & $\mathbf{1 0 0 \%}$ & $\mathbf{1 5 5}$ & $\mathbf{1 0 0 \%}$ \\
\hline
\end{tabular}

The above table indicates that modal verbs are the most used hedging category. This is in line with studies carried out by Hyland (1998) and Farrokhi and Emami (2008). Farrokhi and Emami reported that Hyland attributed this to the ability of modal verbs "to downplay the person making the evaluation" (2008, p. 80). This can also be attributed to the impersonal nature of editorials. The following two examples show the use of modal verbs in the data:

1. The Nigerian Tribune Editorial (17th December, 2018): His fears that such an amendment could confuse voters did not persuade them that his reluctance could be justifiable.

2. The Washington Post Editorial (27th December, 2018): The Russians' goal in 2016 may have been to get Donald Trump elected, but it was also to convince Americans that the democracy we had spent our lives believing in could not be trusted after all.

The next categories are verbs and attributors in both Nigerian and American editorials. As exemplified here, the two categories help in presenting an overt and accurate means for writers to show their level of commitment to propositions: 
1. The New York Times Editorial (28th December, 2018): The last time Chief Justice John Roberts took it upon himself to write the opinion fending off a challenge to the affordable care act, he seemed to signal that he was done entertaining existential threats to the law.

2. The Nigerian Tribune Editorial (6th December, 2018): While initial reports citing military sources put the casualty figure at over 100 soldiers, the chief of Army Staff Lieutenant General Tukur Buratai stated that 23 personnel were killed while 31 were wounded (Attributors).

Attributors function as both hedges and boosters. In the first instance, attributors are regarded as hedges as they provide the sources of information and the editorial writers cannot subsequently be held responsible after a claim has been attributed to a clause. On the other hand, they can also function as boosters after the editorials writers have stated the sources of a claim in their writings. This shows total commitment to proposition as the claim can be confirmed by the readers.

On the use of adverbs as hedges, "reportedly" and "likely" are the most used adverbs in the Nigerian and American editorial analyzed. They are used to put caution to the force of commitment presented through the verbs as shown in these examples:

1. The Nigerian Tribune Editorial (6th December, 2018): Sadly, military rescuers who landed in Metele to evacuate the bodies of their soldier colleagues were reportedly killed in another Boko Haram ambush.

2. The Washington Post Editorial (23rd December, 2018): As has been documented by The Post and other independent fact-checkers, Mr. Trump's sales numbers are wildly inflated and unlikely to materialise.

Other categories (clausal elements, adjectives and nouns) are not frequently used in the data. The category with the least occurrence is nouns. The reason for this may not be unconnected with the fact that words that can function as hedging nouns have been employed as hedging lexical verbs. For examples: believe (lexical verb) for belief (noun), suggest (lexical verb) for suggestion (noun), assume (lexical verb) for assumption (noun), etc.

On the use of boosters in the two sets of editorials, the following exemplify their employment in the data:

1. The New York Times Editorial (31st December, 2018): At least five committees have oversight of piece of it, and even among democrats there are competing visions for various provisions that must (modal verb) be worked through.

2. The Punch Editorial (18th December, 2018): As a newspaper, we reiterate (lexical verb) that only card readers should be used to conduct the 2019 polls.
3. The Nigerian Tribune Editorial (17th December, 2018): Nonetheless, this was definitely (adverb) an issue over which the legislature and the executive could easily have reached a consensus without the unpleasant rancour that attended it.

4. The Washington Post Editorial (17th December, 2018): Russia waged an unprecedented (adjective) campaign, targeting Americans across all segments of society, on platforms large and small.

5. The Nigerian Tribune Editorial (7th December, 2018): And the fact (noun) that they had police protection for their planned illegality will remain one of the sore points in the country's democratic experience.

6. The New York Times Editorial (21st December, 2018): There's no doubt (clausal element) that Mr. Trump was upset about conservatives trashing him for flirting with a wall-free spending bill.

On the use of boosters in the Nigerian editorials, modal verbs were employed more than the other categories. Out of the 66 lexical devices used as boosters, 30 $(45.5 \%)$ are modal verbs. This is followed by the use of adverbs which have 19 (28.8) occurrences. Clausal elements have 7 (10.6) occurrences while nouns, adjectives and lexical verbs are not significantly used as they have $5(7.6 \%), 4(6 \%)$ and $1(1.5 \%)$ occurrences respectively. Concerning the use of boosters in American editorials, the analysis showed that, as it is observable in the Nigerian editorials, modal verbs are also the most used lexical devices with 24 (42.9\%) occurrences out of the total 56 boosters expression used. This is followed by the use of adverbs with 14 occurrences $(25 \%)$. The frequency and percentage of other categories are as follows: clausal elements: 7 (12.5\%), adjectives $6(10.7 \%)$, nouns $5(8.9 \%)$ and lexical verb $0(0 \%)$ respectively. The analysis is shown in the table below:

Table 3: Frequency of Occurrence of Boosters Categories in Nigerian and American Editorials.

\begin{tabular}{lcccc}
\hline \multicolumn{1}{c}{$\begin{array}{c}\text { Booster } \\
\text { categories }\end{array}$} & \multicolumn{2}{c}{ Nigerian editorials } & \multicolumn{2}{c}{ American editorials } \\
\cline { 2 - 5 } \multicolumn{1}{c}{ Frequency } & Percentage & Frequency & Percentage \\
\hline Modal verbs & 30 & $45.5 \%$ & 24 & $42.9 \%$ \\
Lexical verbs & 01 & $1.5 \%$ & 0 & $0 \%$ \\
Adverbs & 19 & $28.8 \%$ & 14 & $25 \%$ \\
Adjectives & 04 & $6 \%$ & 06 & $10.7 \%$ \\
Nouns & 05 & $7.6 \%$ & 05 & $8.9 \%$ \\
Clausal & 07 & $10.6 \%$ & 07 & $12.5 \%$ \\
elements & & & & \\
\hline Total & $\mathbf{6 6}$ & $\mathbf{1 0 0 \%}$ & $\mathbf{5 6}$ & $\mathbf{1 0 0 \%}$ \\
\hline
\end{tabular}

The table above shows that there is no significant difference in the use of all the booster categories of both Nigerian and American editorials. For example, while lexical verb has just one occurrence in the Nigerian editorials, it does not have any occurrence in the American editorials. This is definitely insignificant. 
It is observable from the data analysis and discussion above that both the Nigerian and American editorial writers greatly employed both hedging and boosting expressions. The implication of this is that there is no cultural difference in the use of hedges and boosters in the editorials of the two cultures. While the Nigerian editorials analyzed had 149 hedges and 66 boosters, the American editorials had 155 hedges and 56 boosters respectively. Thus, there is no significant difference. This implies that it is imperative for writers of persuasive texts such as editorials to strike a balance between presenting claims with total conviction and with less commitment. This is even done within the same sentence where total conviction is expressed together with less commitment. Two examples are given below:

i. The Punch Editorial (21st December, 2018): Clearly, as things stand, development and progress elude the country, marking out the Information Minister's assertion as being blatantly false.

ii. The New York Times Editorial (21st December, 2018): But Senate leaders made clear that nothing was likely to move until a new bipartisan compromise could be reached.

This study has also shown that another way of hedging is through the use of attributors. This is also a way of presenting claims with conviction. In the first instance, when claims presented in the editorial are referenced, the writers cannot be held responsible for any possible fallout as a result of the claims. On the other hand, it shows that the claims can be verified from the attributed source; this represents conviction. Therefore, the use of both hedges and boosters is essential in writing persuasive texts such as editorials.

\section{CONCLUSION}

This paper has focused on the employment of hedging and boosting devices as modality markers in the Nigerian and American editorials. The study reveals that both sets of editorial writers employ hedges and boosters as expressions of doubt and conviction in their texts. All the categories of lexical devices are used as hedges. For the expression of boosters, five of the six categories of lexical devices are employed more than once, except lexical verbs. There is only one occurrence of lexical verbs as boosters in the Nigerian editorials and they are not used in the American editorials. This difference is insignificant. The reason for this is that in the two sets of editorials, modal verbs and adverbs are the most used lexical devices for the expression of conviction. Also, although attributors are categorized as hedges, they perform the dual roles of reducing the force of commitment of claims and referencing claims to create conviction.
Concerning the similarities and differences in the employment of hedges and boosters in the data, it is found out that while there are substantial similarities, there are no significant differences. Two reasons may be attributed to this. One, for someone to become an editorial writer in an English as a Second Language environment such as Nigeria, it is expected that one must have attained a great level of education and be proficient in English language. As such, the writing would be close to native-like writing. Secondly, editorial as a genre requires an acceptable form of writing irrespective of cultural and political background. In other words, it requires writers to balance between conviction and doubt in their propositions. Editorials are seen as "some of the best examples persuasive writings" (Connor, 1996:144), and the hallmark of a good editorial is the employment of both hedges and boosters by the writers. Thus, at the level of editorials, there does not appear to be cultural differences in the employment of hedges and boosters.

However, there are limitations to this study. One, the study considered only four newspapers: two from Nigeria and two from America. As such, limited data have been explored. Probably, a larger set of data may reveal different findings in the employment of lexical devices as hedges and boosters in editorials of different cultures. This is a cross-cultural study, and the lexical devices for hedges and boosters are generally contrasted for possible differences that may be attributed to cultural differences. However, the study does not reveal any difference. Therefore, crosscultural studies that focus on similarities and differences in the use and placement of hedges and boosters in each rhetorical structure (section) of editorials can be valuable in this regard. For example, the expression of doubt and conviction in the concluding parts of editorials of different culture can be investigated.

\section{REFERENCES}

A'Ibom assembly mayhem, threat to democracy. (2018, December 4). The Punch, p.20.

Alo, M.A. (2013). English modality as a rhetorical tool in Nigerian political manifestoes. In A. Ogunsiji, A. Kehinde \& A. Odebunmi (Eds.), Language, literature and discourse: A festschrift in honour of Professor A. 'Lekan Oyeleye (pp. 125-138). Ibadan: Stirling-Horden Publishers Ltd.

Ansary, H. \& Babaii, E. (2004). The generic integrity of newspaper editorial: A systemic functional view of text for contrastive rhetoric research. Regional Language Centre Journal 40(2), 211249. doi: 10.1177/0033688205060051.

Ansary, H. \& Babaii, E. (2009). A cross-cultural analysis of English newspaper editorials: A systemic functional perspective. Asian EFL Journal.6, 158. doi: $10.1177 / 0033688209105867$. 
Badeh's murder and unbridled insecurity. (2018, December 21). The Punch, p. 20.

Bandits' killing of 16 policemen in Zamfara. (2018, December 13). The Nigerian Tribune, p. 13.

Buhari's rejection of electoral act (amendment) bill. (2018, December 18). The Punch, p. 20.

Cleaning the congressional stables. (2018, December, 31). The New York Times. Retrieved from https://www.nytimes.com/2018/12/31/opinion/e ditorials/democrats-reform-house.html.

Connor, U. (1996), Contrastive rhetoric: Crosscultural aspects of second-language writing. Cambridge: Cambridge University Press.

Crismore, A., Markkanen, R. \& Steffensen, M. (1993). Metadiscourse in persuasive writing: A study of texts written by American and Finnish university students. Written Communication, 10(1), 39-71. doi: $10.1177 / 0741088393010001002$.

Democrats used Russian tactics in Alabama. Now they must swear them off. (2018, December 27). The Washington Post. Retrieved from https://www. washingtonpost.com/opinions/democrats-usedrussian-tactics-in-alabama-now-they-mustswear-them-off/2018/12/27/5b97c332-094111e9-a3f0-71c95106d96a_story.html.

EFCC and 2019 elections' credibility. (2018, December 11). The Punch, p. 22.

Farrokhi, F. \& Emami, S. (2008). Hedges and boosters in academic writing: Native vs. non-native research articles in applied linguistics and engineering. The Journal of Applied Linguistics, 1(2), 62-97.

FG's verdict on electoral promises. (2018, December 27). The Nigerian Tribune, p.13.

Hinkel, E. (2002). Second language writer's text: Linguistic and rhetorical features. New Jersey: Lawrence Erlbaum Associates.

Holmes, J. (1982). Expressing doubt and certainty in English. RELC Journal, 3, 9-28. doi: 10.1177/ 003368828201300202.

Holmes, J. (1988). Doubt and certainty in ESL textbooks. Applied Linguistics, 9(1), 20-44. doi: 10.1093/applin/9.1.21.

Hyland, K. (1996). Talking to the academy: Forms of hedging in science research articles. Written Communication, 13(2), 251-281. doi: 10.1177/ 0741088396013002004.

Hyland, K. (1998). Hedges, boosters and the negotiation of academic knowledge. TEXT, 18(3), 349382. doi: 10.1515/text.1.1998.18.3.349.

Hyland, K., \& Milton, J. (1997). Qualification and certainty in L1 and L2 students' writing. Journal of Second Language Writing, 6(2), 183-205. doi: 10.1016/S1060-3743(97)90033-3.

Jegede, O.O. (2015). Language and ideology in the media: A study of Nigerian newspaper editorials.
International Journal of English Literature and Culture, 3(3), 76-84. doi: 10.14662/IJELC2015. 016.

Lewin, B.A. (2005). Hedging: An exploratory study of authors' and readers' identification of 'toning down' in scientific texts. Journal of English for Academic Purposes, 4, 163-178. doi: 10.1016/ j.jeap.2004.08.001.

Medubi, O.C. (2007). The fundamentals of journalism. In O. Obafemi, G.A. Ajadi \& V.A. Alabi (Eds.). Critical perspectives on English language and literature (pp. 105-116). Ilorin: The Department of English.

Myers, G. (1989). The pragmatics of politeness in scientific articles. Applied Linguistics, 10 (1), 135. doi: 10.1093/applin/10.1.1.

Quirk, R., Greenbaum, S., Leech, G., Starvik, J. (1985). A comprehensive grammar of English language. London and New York: Longman.

Russian's support for Trump's election is no longer disputable. (2018, December 17). The Washington Post. Retrieved from https://www.washingtonpost.com/opinions/russias-support-for-trumpselection-is-no-longer-disputable/2018/12/17 /d194870e-023a-11e9-9122-82e98f91ee6f_story. html.

Ryan Zinke, into the sunset. (2018 December, 15). The New York Times. Retrieved from https://www. nytimes.com/2018/12/15/opinion/ryan-zinkeinterior-resigns-trump.html.

Salager-Meyer, F. (1994). Hedges and textual communicative function in medical English written discourse. English for Specific Purposes, 13(2), 121-140. doi: 10.1016/0889-4906(94)90013-2.

Sedaghat, A., et al (2015). Cross cultural analysis of hedges in Persian and English editorial columns. International Journal of Language Learning and Applied Linguistics World, 8(1), 37-50.

Shutdown? More like a breakdown. (2018, December 21). The New York Times. Retrieved from https://www.nytimes.com/2018/12/21/opinion/g overnment-shutdown-2018-trump.html.

The electoral act amendment controversy. (2018, December, 17). The Nigerian Tribune, p. 13.

The latest chance for D.C. voting rights. (2018, December 26). The Washington Post. Retrieved from https://www.washingtonpost.com/opinions/thelatest-chance-for-dc-voting-rights/2018/12/26/ 30361fb8-f1c2-11e8-bc79-68604ed88993_ story.html.

The Macabre dance in Akwa Ibom. (2018, December 7). The Nigerian Tribune, p. 13.

The Metele attack. (2018, December 6). The Nigerian Tribune, p. 13.

The unlearned lessons of Jamal Khashoggi's murder. (2018, December 23). The Washington Post. 
Retrieved from https://www.washingtonpost. com/opinions/global-opinions/the-unlearnedlessons-of-jamal-khashoggis-murder/2018/12/ 23/8584328e-0220-11e9-b6a9-0aa5c2fcc9e4_ story.html.

The war on truth spreads. (2018, December 9). The New York Times. Retrieved from https://www. nytimes.com/2018/12/09/opinion/media-dutertemaria-ressa.html.

Vassileva, I. (2001). Commitment and detachment in English and Bulgarian academic writing. English for Specific Purposes, 20, 83-102. doi: 10.1016/ S0889-4906(99)00029-0.
When security votes spending turns genocidal. (2018, December 12). The Punch, p. 20.

Why Congo's election on Sunday will be a travesty. (2018, December 28). The Washington Post. Retrieved from https://www.washingtonpost. com/opinions/why-congos-election-on-sundaywill-be-a-travesty/2018/12/28/ec5a46b2-0ac011e9-a3f0-71c95106d96a_story.html.

Will the Supreme Court save Obamacare again? (2018December 28). The New York Times. Retrieved from https://www.nytimes.com/2018/ 12/28/opinion/trump-obamacare-supremecourt.ht ml. 